University of Wollongong

Research Online

Faculty of Engineering and Information

Faculty of Engineering and Information

Sciences - Papers: Part A

Sciences

January 2016

\title{
Study on the interface behavior of a geosynthetics-reinforced fouled ballast using the discrete element method
}

\author{
Ngoc Trung Ngo \\ University of Wollongong, trung@uow.edu.au \\ Buddhima Indraratna \\ University of Wollongong, indra@uow.edu.au \\ Cholachat Rujikiatkamjorn \\ University of Wollongong, cholacha@uow.edu.au
}

Follow this and additional works at: https://ro.uow.edu.au/eispapers

Research Online is the open access institutional repository for the University of Wollongong. For further information contact the UOW Library: research-pubs@uow.edu.au 


\title{
Study on the interface behavior of a geosynthetics-reinforced fouled ballast using the discrete element method
}

\author{
Abstract \\ Railways offer an efficient and economic transport mode in many parts of the developed countries \\ including Australia, China and USA. Ballast layer is designed as a load bearing layer for rail tracks and to \\ be free draining, but when the ballast voids are wholly or partially impeded due to the intrusion of fine \\ particles, the ballast can be considered to be fouled. Fouling causes a reduction in the drainage capacity \\ of ballast, thereby reducing the track resiliency and triggering high maintenance costs. Geosynthetics are \\ commonly used in railway construction for reinforcement and stabilization purposes. When railway \\ ballast becomes fouled the beneficial effect of the geosynthetics could decrease significantly. This paper \\ presents a study of how the interface behavior of geosynthetics-ballast copes with fouling using discrete \\ element modelling (DEM) of large-scale direct shear tests. A series of large-scale direct shear tests for \\ coal fouled ballast were carried out in the laboratory and were then simulated in the DEM. Shear stress- \\ strain and volumetric dilation responses obtained from the DEM simulations were in reasonable \\ agreement with those measured experimentally. The contact force distributions of fresh and fouled \\ ballast were captured and shown that the fouled ballast exhibited higher number of contact forces \\ compared to the fresh ballast assembly. This is due to coal fines accumulated in voids among large \\ particles then partially carry and transmit contact forces across the assembly. Strains developed \\ horizontally across the geogrid were also analyzed in this study.
}

\section{Keywords}

discrete, ballast, fouled, element, reinforced, method, geosynthetics, behavior, interface, study

\section{Publication Details}

Ngo, N., Indraratna, B. \& Rujikiatkamjorn, C. (2016). Study on the interface behavior of a geosyntheticsreinforced fouled ballast using the discrete element method. In K. R. Reddy, N. Yesiller, D. Zekkos, A. Farid \& A. De (Eds.), Geo-Chicago 2016: Sustainable Materials and Resource Conservation (pp. 730-738). Reston, United States: American Society of Civil Engineers. 


\title{
Study the Interface Behavior of Geosynthetics-reinforced Fouled Ballast using Discrete Element Method
}

\author{
Ngoc Trung Ngo ${ }^{1}$, Buddhima Indraratna ${ }^{2}$ FASCE, Cholachat Rujikiatkamjorn ${ }^{3}$. \\ ${ }^{1}$ Lecturer, School of Civil, Mining and Environmental Engineering, Faculty of \\ Engineering and Information Sciences, University of Wollongong, Wollongong, \\ NSW 2522, Australia. Email: trung@uow.edu.au \\ ${ }^{2}$ Research Director, Professor of Civil Engineering, Centre for Geomechanics and \\ Railway Engineering, Faculty of Engineering and Information Sciences, ARC Centre \\ of Excellence for Geotechnical Science and Engineering, University of Wollongong, \\ Wollongong, NSW 2522, Australia. Email: indra@uow.edu.au \\ ${ }^{3}$ Associate Professor, Centre for Geomechanics and Railway Engineering, Faculty of \\ Engineering and Information Sciences, ARC Centre of Excellence for Geotechnical \\ Science and Engineering, University of Wollongong, Wollongong, NSW 2522, \\ Australia. Email: cholacha@uow.edu.au
}

\begin{abstract}
Railways offer an efficient and economic transport mode in many parts of the developed countries including Australia, China and USA. Ballast layer is designed as a load bearing layer for rail tracks and to be free draining, but when the ballast voids are wholly or partially impeded due to the intrusion of fine particles, the ballast can be considered to be fouled. Fouling causes a reduction in the drainage capacity of ballast, thereby reducing the track resiliency and triggering high maintenance costs. Geosynthetics are commonly used in railway construction for reinforcement and stabilization purposes. When railway ballast becomes fouled the beneficial effect of the geosynthetics could decrease significantly. This paper presents a study of how the interface behavior of geosynthetics-ballast copes with fouling using discrete element modelling (DEM) of large-scale direct shear tests. A series of large-scale direct shear tests for coal fouled ballast were carried out in the laboratory and were then simulated in the DEM. Shear stress-strain and volumetric dilation responses obtained from the DEM simulations were in reasonable agreement with those measured experimentally. The contact force distributions of fresh and fouled ballast were captured and shown that the fouled ballast exhibited higher number of contact forces compared to the fresh ballast assembly. This is due to coal fines accumulated in voids among large particles then partially carry and transmit contact forces across the assembly. Strains developed horizontally across the geogrid were also analyzed in this study.
\end{abstract}

\section{INTRODUCTION}

Ballast is an important component of railway tracks used as a load carrying layer and for maintaining track alignment (Selig and Waters 1994). The main purposes are to distribute the train load to the underlying layers at a reduced and acceptable stress 
level and to provide track drainage conditions. Upon repeated train loading, ballast deteriorates and spreads laterally causing track instability (Indraratna et al. 2011; Ngo et al. 2014). In addition to this, due to progressive degradation and the infiltration of fine particles or mud-pumping from below layers, ballast gets fouled, which decreases the shear strength and increases the deformation of ballasted tracks (Indraratna et al. 2013; Tutumluer et al. 2008). Geogrids have been widely used in rail tracks to reinforce ballast and to increase the duration of track serviceability (Raymond 2002; Brown et al. 2007; Indraratna et al. 2014). It has been documented that due to the mechanical interlock with ballast grains, geogrids can reduce lateral displacements and degradation of ballast (Bathurst and Raymond 1987; Indraratna et al. 2013). Despite these benefits, current literature on the interface behavior of geogrid-ballast is still limited both in experimental study and numerical simulation, particularly when ballast becomes fouled (Ngo et al. 2014).

The large-scale direct shear apparatus used in this study consists of a $300 \mathrm{~mm}$ x 300 $\mathrm{mm}^{2}$ square steel box, $200 \mathrm{~mm}$ high. Ballast was collected from Bombo quarry, New South Wales, Australia, then cleaned and sieved according to Australia Standards (AS 2758.7, 1996). Coal fines were used as fouling contaminant and the Void Contamination Index (VCI) introduced earlier by (Indraratna et al. 2010) was applied to measure the degree of fouling, as shown:

$V C I=\frac{1+e_{f}}{e_{b}} \times \frac{G_{s b}}{G_{s f}} \times \frac{M_{f}}{M_{b}} \times 100$

where $e_{f}$ : the void ratio of fouling material; $e_{b}$ : the void ratio of fresh ballast; $G_{s b}$ : the specific gravity of ballast; $G_{s f}:=$ the specific gravity of fouling material; $M_{f}$ : the dry mass of fouling material; $M_{b}$ : the dry mass of fresh ballast.

Particle size distributions of materials tested in this study are presented in Figure 1. Large-scale direct shear tests for ballast reinforced by the $40 \mathrm{~mm}$ x $40 \mathrm{~mm}$ geogrid were carried out to shear to a displacement of $\Delta h=37 \mathrm{~mm}$ and detailed results discussed elsewhere by Indraratna et al. (2011), while some of these data were used in this study to calibrate DEM models. Experimental data highlighted that the peak shear stress of ballast increases with an increase in normal stress and then decreases with an increase level of fouling. Strain softening and dilation response are obtained for all tests, where the higher normal stress $\sigma_{n}$, the greater shear strength, and smaller dilations are observed. Tutumluer et al. (2008) also presented similar shear stressstrain behaviour of railway ballast that they measured in the laboratory. 


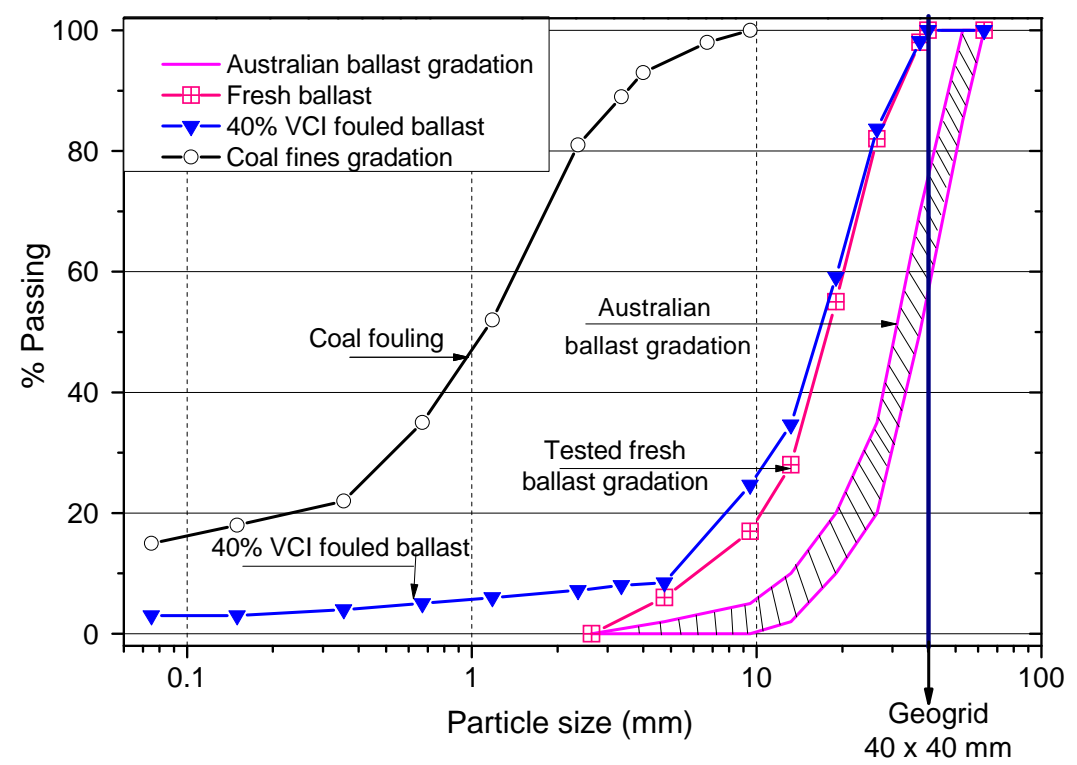

FIG. 1. Particle size distributions of materials tested

\section{DISCRETE ELEMENT MODELLING FOR BALLAST}

The discrete element method (DEM) introduced by Cundall and Strack (1979) has been often used to simulate granular materials (Ngo et al. 2014; Lu and McDowell 2008; Indraratna et al. 2015; Ngo et al. 2015 ). The DEM method is able to accurately model the discrete nature of ballast aggregates by providing an insight into micromechanical factors such as particle shape, contact force distributions developed among particles that are difficult to measure in the laboratory. A large-scale shear box (300mm long $\times 300 \mathrm{~mm}$ wide $\times 200 \mathrm{~mm}$ high) is modelled in DEM with rigid walls to simulate fresh and fouled ballast ( $\mathrm{VCI}=40 \%$ ), as shown in Figures $2 \mathrm{~b}-\mathrm{c}$. The simulated ballast were then placed in the shear box at random orientations and compacted to a void ratio of 0.82 (i.e. porosity of 45\%) to mimic laboratory conditions. Fouled ballast (VCI $=40 \%$ ) was simulated by placing 145,665 of $1.5 \mathrm{~mm}$ diameter spherical balls into the pore spaces of fresh ballast (Figure 2c). A geogrid with $40 \mathrm{~mm} \times 40 \mathrm{~mm}$ apertures were simulated by bonding small spherical balls together (i.e. balls having $2 \mathrm{~mm}$ radius at ribs and $4 \mathrm{~mm}$-radius at junctions). Largescale direct shear tests for ballast and tensile tests for geogrid were carried out to determine required input parameters for DEM modelling. By calibrating with experimental results reported by Indraratna et al. (2011) and Ngo et al. (2014), a set of micromechanical parameters adopted for DEM simulations of ballast, geogrid, and coal fines are presented in Table 1.

\section{RESULTS AND DISCUSSION}

\section{Shear stress-displacement and volumetric change analysis}

A series of large scale direct shear tests were carried out in the laboratory and DEM simulations to investigate shear stress-displacement response of fresh and coal-fouled 
ballast stabilized by geogrids. Figure 3 shows the comparisons of shear stress-strain response and volumetric change obtained from DEM and those measured in the laboratory by Indraratna et al. (2011).

Table 1.Micromechanical Parameters of Geogrid, Ballast and Coal Fines

\begin{tabular}{|c|c|c|l|}
\hline Parameter & Geogrid & Ballast & Coal fines \\
\hline Particle density $\left(\mathrm{kg} / \mathrm{m}^{3}\right)$ & 800 & 2700 & 800 \\
Coefficient of friction & 0.5 & 0.8 & 0.2 \\
Contact normal stiffness, $k_{n}(\mathrm{~N} / \mathrm{m})$ & $1.77 \times 10^{7}$ & $0.52 \times 10^{8}$ & $1.27 \times 10^{4}$ \\
Contact shear stiffness, $k_{s}(\mathrm{~N} / \mathrm{m})$ & $0.88 \times 10^{7}$ & $0.52 \times 10^{8}$ & $1.27 \times 10^{4}$ \\
Contact normal stiffness of wall-particle, $\mathrm{k}_{\mathrm{n}-\mathrm{wall}}(\mathrm{N} / \mathrm{m})$ & $1 \times 10^{8}$ & $1 \times 10^{8}$ & $1 \times 10^{8}$ \\
Shear stiffness of wall of wall-particle, $\mathrm{k}_{\mathrm{s} \text {-wall }}(\mathrm{N} / \mathrm{m})$ & $1 \times 10^{8}$ & $1 \times 10^{8}$ & $1 \times 10^{8}$ \\
Parallel bond radius multiplier, $r_{p}$ & 0.5 & & \\
Parallel bond normal stiffness, $k_{n p}(\mathrm{kPa} / \mathrm{m})$ & $5.68 \times 10^{8}$ & \\
Parallel bond shears stiffness, $k_{s p}(\mathrm{kPa} / \mathrm{m})$ & $5.68 \times 10^{8}$ & & \\
Parallel bond normal strength, $\sigma_{n p}(\mathrm{MPa})$ & 456 & & \\
Parallel bond shear strength, $\sigma_{s p}(\mathrm{MPa})$ & 456 & & \\
\hline
\end{tabular}

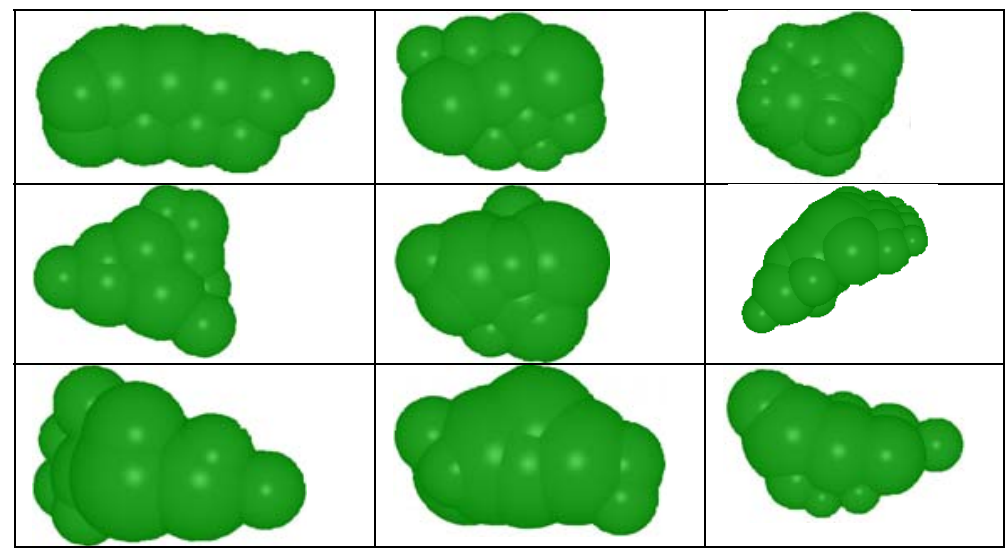

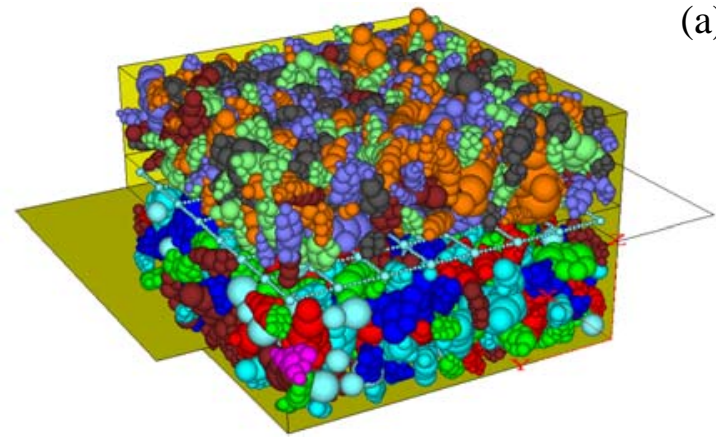

(b) (a)

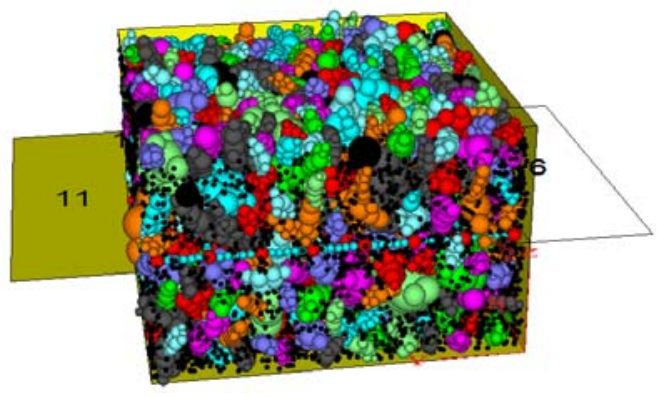

(c)

FIG. 2. DEM models ot direct shear test (a) ballast particie shapes; (b) DEM models for fresh ballast; (c) DEM models for fouled ballast (modified after Indraratna et al. 2014) 
It is seen that results obtained from DEM simulation reasonably agree with those measured experimentally. Compared to the fresh ballast $(\mathrm{VCI}=0 \%)$ the fouled ballast (VCI $=40 \%$ ) show a lesser peak shear stress at a given normal stress. For all simulations, the ballast exhibits compression initially, followed by significant dilation. Coal particles act as a lubricant thus would facilitate particles to displace and to rearrange, which in turns increase dilation. It is noted that there are some discrepancies in volumetric change response obtained from the numerical simulations and those measured in the laboratory. This can be attributed to particle angularity as well as particle breakage that did not accurately capture in the current DEM analysis. The results also indicate a sudden decrease in shear stress at 5-7\% shear strain, before picking up the load again, which further supports the initiation of particle degradation at this level of shear strain (Figure 3). Despite this disparity, the DEM model proposed in this study is able to capture the shear stress-strain and volumetric dilation of fresh and coal-fouled ballast under any given normal stress.

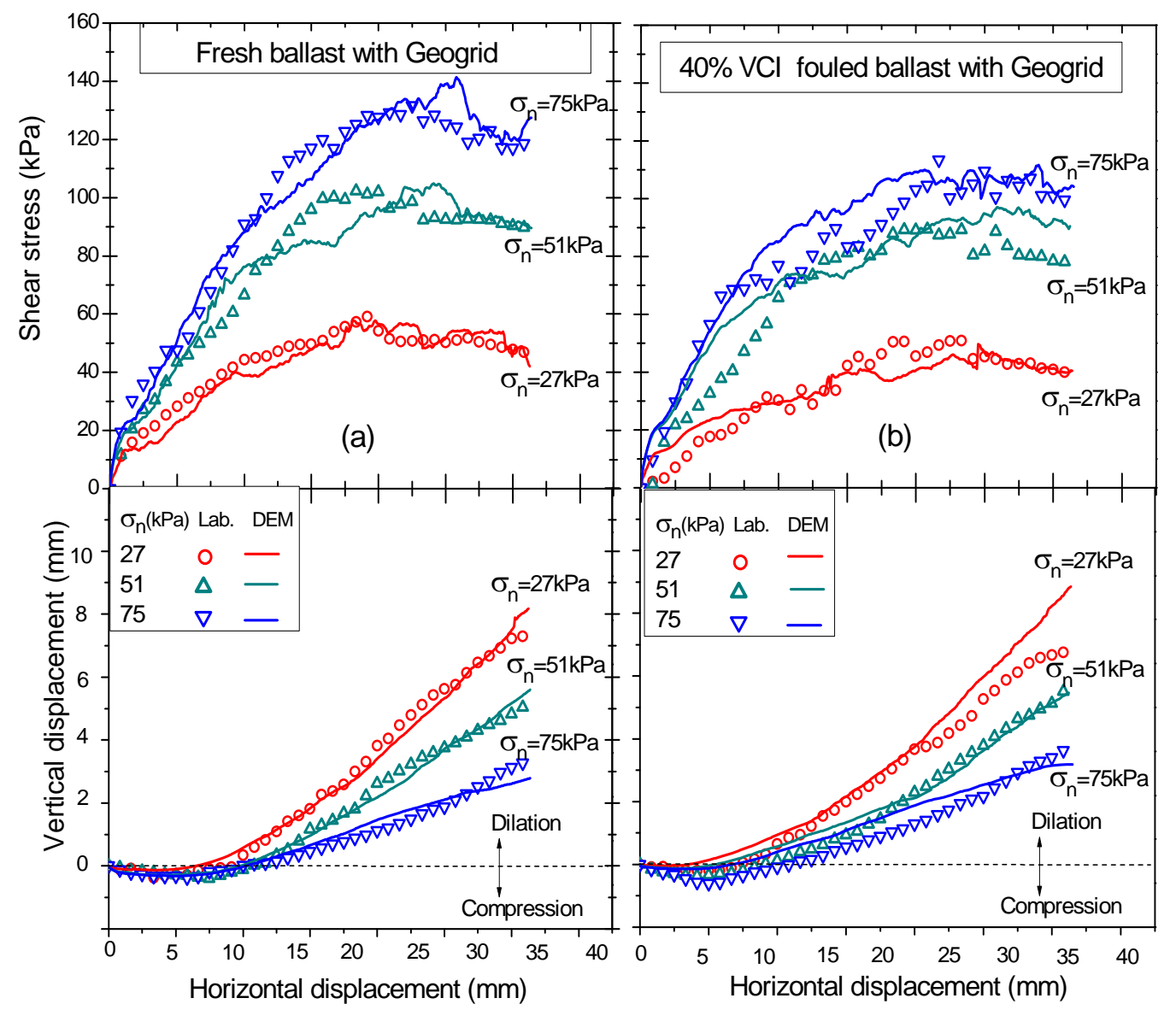

FIG. 3. Comparisons between the DEM simulation and experimental data of ballast reinforced by geogrid: (a) fresh ballast, (b) $40 \%$ VCI fouled ballast (modified after Ngo et al. 2014) 


\section{Contact Force Distribution and Contours of Strain Developed in the Geogrids}

Figure 4 shows the contact force distributions of fresh and fouled ballast (VCI=40\%) with and without geogrid reinforcement subjected to a normal stress of $51 \mathrm{kPa}$ and a shear displacement of $18 \mathrm{~mm}$. For the purpose of clarification, only those contact forces with a magnitude exceeding the average value in the assembly are presented. It is seen that the fouled ballast shows denser contact chains and lesser maximum contact forces compared to those in the fresh ballast assembly. This is attributed to the presence of small particles accumulated in voids among the large particles and then partially carried and transmitted contact forces across the assembly. Compared to the unreinforced ballast, the geogrid-reinforced ballast experiences a considerable increase in the number and magnitude of contact forces at the interface where it is believed due potentially to the interlocking effect occurring between the geogrids and ballast.

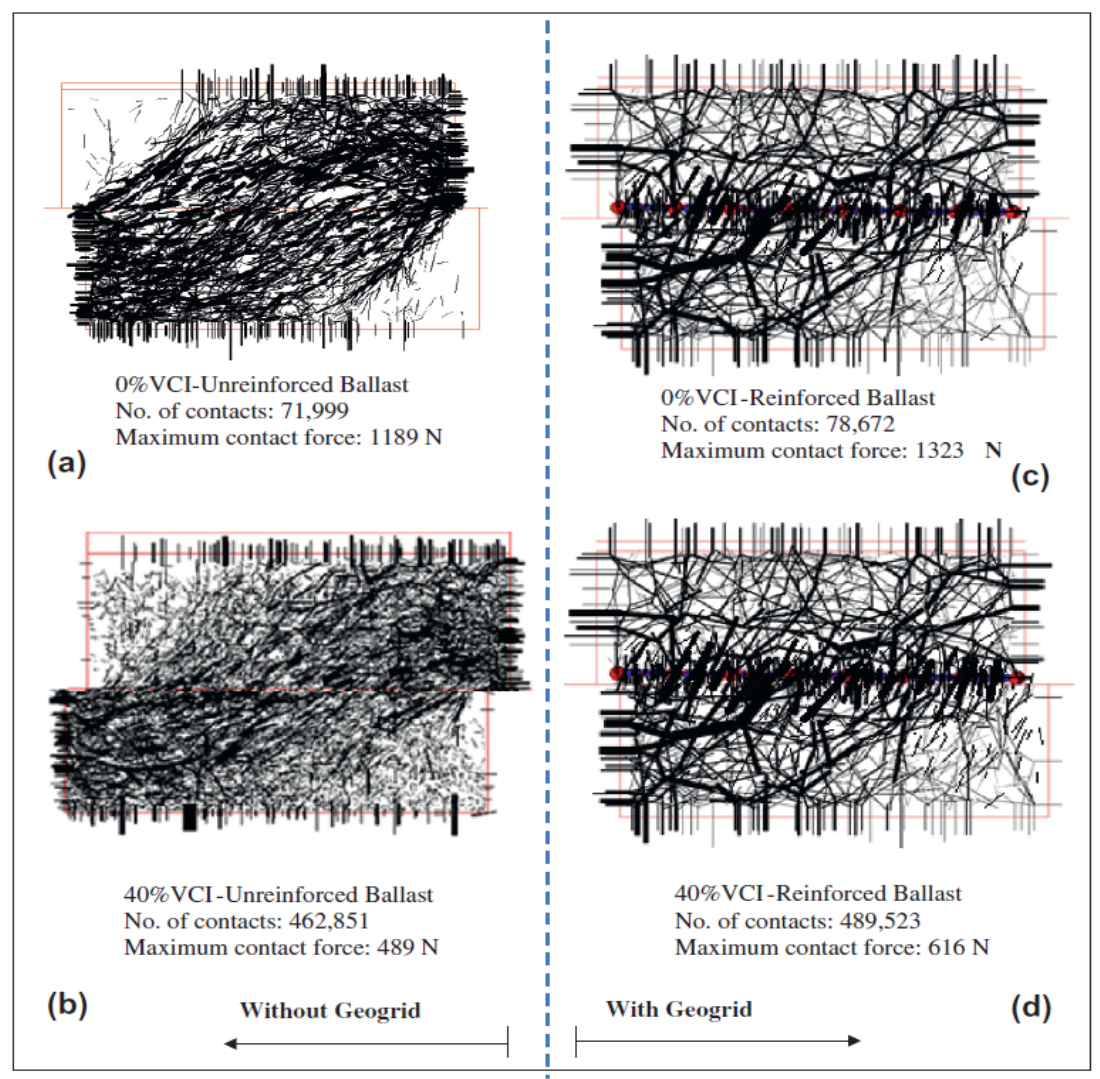

FIG. 4. Distribution of contact forces: (a) unreinforced-fresh ballast; (b) unreinfoced fouled ballast; (c) reinforced fresh ballast; (d) reinforced fouled ballast (modified after Ngo et al. 2014)

Strains that developed in geogrids did not measure in the laboratory due to the complexity of attaching strain gauges to the geogrids and difficulty of preventing the 
strain gauge from being damaged caused by the sharp edges of ballast and induced vibration. Taking advantage of the DEM simulation, strains in the horizontal shearing direction that develop across the geogrid are captured and presented in this study.

Figures 5a-b present contours of strains developed across the geogrid at the end of shear test for fresh ballast and fouled ballast, respectively. It can be seen that strains develop non-uniformly across the geogrid and the magnitude of strain may depend on the interlock occurring between the geogrid and ballast particles. The geogrid in $40 \%$ VCI fouled ballast assembly experience a slightly lower maximum strain than those in the fresh ballast (i.e. 1\% strain for fouled ballast compared to $1.4 \%$ strain in fresh ballast). This would be attributed to the decreased interlocking effect of the geogrid and ballast due to the presence of coal fines clogging at their interfaces.

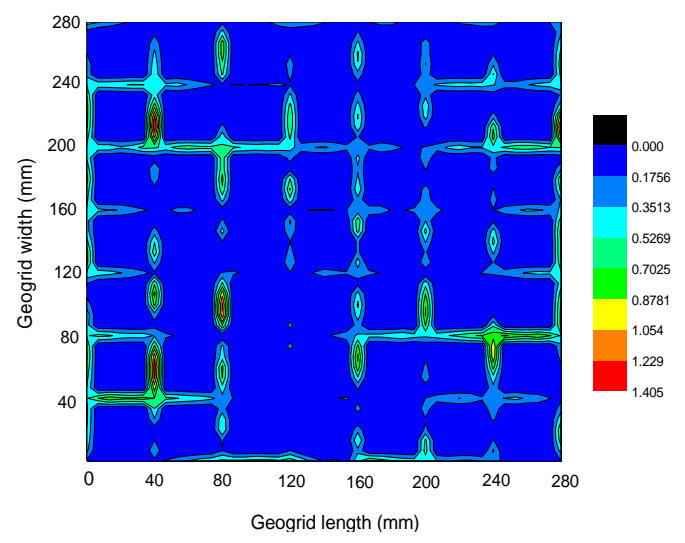

(a)

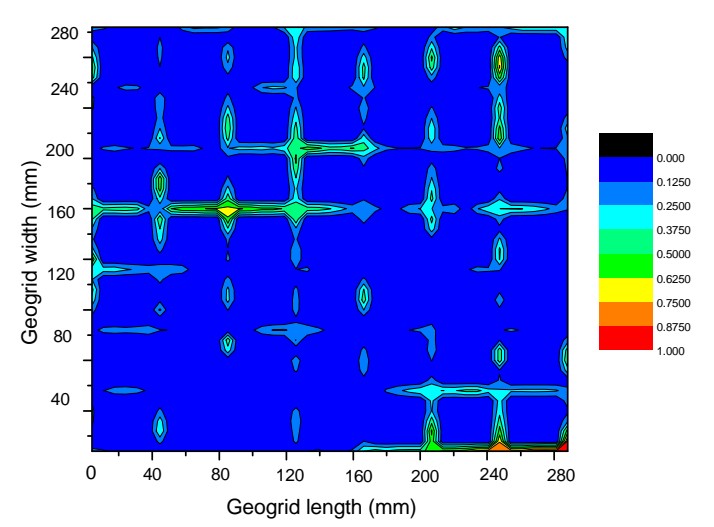

(b)

Fig. 5. Contour strain (in horizontal shearing direction) developed across the geogrid in at the end of the test (units of strains in percent): (a) Fresh ballast; (b) $40 \%$ VCI fouled ballast (modified after Ngo et al. 2014)

\section{CONCLUSIONS}

This paper presents results of large-scale direct shear tests and discrete element method (DEM) to study the performance of geogrids reinforced fouled ballast. The results showed that geogrids increases the peak shear stress and decreases ballast dilation at a given VCI. This was justified by the interlocking effect between the geogrids and ballast grains at the interface. Conversely, coal fines acting as a lubricant coated the surfaces of ballast grains, which subsequently reduced the interparticle friction and the shearing resistance of fouled ballast assembly. DEM simulations were conducted to study shear stress-strain response and corresponding volumetric change of fresh and fouled ballast (VCI=40\%). For a given normal stress and degree of fouling, the DEM simulation captured the shear stress-strain behavior of the fresh and fouled ballast as measured experimentally. The contact force distributions were also examined and indicated that the fouled ballast sample exhibited much denser contact force distribution and lesser maximum contact forces 
than those for the fresh ballast. Strains developed across the geogrid were also captured in the DEM simulations.

\section{ACKNOWLEDGMENTS}

The Authors would like to appreciate the financial support provided by Australian Research Council, Cooperative Research Centre for Rail Innovation, and support from the Centre for Geomechanics and Railway Engineering, University of Wollongong, NSW, Australia for the funding of this research. A significant portion of these contents were reproduced with kind permission from the Journal of Geotechnical and Geoenvironmental Engineering-ASCE, Computers and Geotechnics.

\section{REFERENCES}

Australian Standard: AS2758.7 (1996). “Aggregates and rock for engineering purposes; Part 7: Railway ballast”. Sydney, NSW, Australia

Bathurst, R.J., and Raymond, G.P.(1987). "Geogrid reinforcement of ballasted track". Transportation Research Record. 1153: 8-14.

Brown, S. F., Kwan, J. , and Thom, N. H. (2007). "Identifying the key parameters that influence geogrid reinforcement of railway ballast". Geotextiles and Geomembranes. 25(6): 326-335.

Cundall, P. A. , and Strack, O. D. L. (1979). "A discrete numerical model for granular assemblies". Géotechnique. 29(1): 47-65.

Indraratna, B., Nimbalkar, S. , and Tennakoon, N. (2010). "The behaviour of ballasted track foundations: Track drainage and geosynthetic reinforcement". GeoFlorida 2010: Advances in Analysis, Modeling \& Design (GSP 199). Fratta, D., Puppala, A. and Muhunthan, B. (Eds.) 2378-2387.

Indraratna, B., Ngo, N. T. , and Rujikiatkamjorn, C. (2011). "Behavior of geogridreinforced ballast under various levels of fouling". Geotextiles and Geomembranes. 29(3): 313-322.

Indraratna, B., Ngo, N. T , and Rujikiatkamjorn, C. (2013). "Deformation of coal fouled ballast stabilized with geogrid under cyclic load". Journal of Geotechnical and Geoenvironmental Engineering-ASCE. 139(8): 1275-1289.

Indraratna, B., Ngo, N. T, Rujikiatkamjorn, C. , and Vinod, J. (2014). "Behavior of fresh and fouled railway ballast subjected to direct shear testing: Discrete element simulation". International Journal of Geomechanics. 14(1): 34-44.

Indraratna, B., Ngo, N. T., Rujikiatkamjorn, C. , and Sloan, S. W. (2015). "Coupled discrete element-finite difference method for analysing the load-deformation behaviour of a single stone column in soft soil". Computers and Geotechnics. 63: 267-278.

Lu, M. , and McDowell, G. R. (2008). "Discrete element modelling of railway ballast under triaxial conditions". Geomechanics and Geoengineering: An International Journal. 3(4): 257--270.

Ngo, N. T., Indraratna, B. , and Rujikiatkamjorn, C. (2014). "DEM simulation of the behaviour of geogrid stabilised ballast fouled with coal". Computers and Geotechnics. 55(2014): 224-231. 
Ngo, N. T., Indraratna, B., Rujikiatkamjorn, C., and M. Mahdi Biabani. (2015). "Experimental and discrete element modelling of geocell-stabilised subballast subjected to cyclic loading". Journal of Geotechnical and Geoenvironmental Engineering-ASCE. DOI: 10.1061/(ASCE)GT.1943-5606.0001431.

Raymond, G. P. (2002). "Reinforced ballast behaviour subjected to repeated load". Geotextiles and Geomembranes. 20(1): 39-61.

Selig, E. T. , and Waters, J. M. (1994). "Track geotechnology and substructure management”. Thomas Telford, London.

Tutumluer, E., Dombrow, W. , and Huang, H. (2008). "Laboratory characterization of coal dust fouled ballast behaviour". AREMA 2008 Annual Conference \& Exposition, Salt Lake City, UT, USA. 